\title{
Crisis is the property of complex systems
}

\author{
Mikhail B. Ignatyev \\ St-Petersburg State University of Aerospace Instrumentation ,67 Bolshaja Morskaja uliza, St-Petersburg, Russia
}

Email address:

ignatmb@mail.ru (M. B. Ignatyev)

\section{To cite this article:}

Mikhail B. Ignatyev. Crisis is the Property of Complex Systems. Journal of World Economic Research. Vol. 1, No. 1, 2012 , pp. 1-5. doi: 10.11648/j.jwer.20120101.11

\begin{abstract}
We can understand of crisis nature only by means of investigation of complex systems. Our socio-economical system is very complicated system. Any complex system interacts with its changing environment and its viability depends on its adaptability. The number of arbitrary coefficients in the structure of equivalent equations of complex system changes in the process of learning. In systems with more than six variables, the number of arbitrary coefficients increases first, and then, passing through the maximum, begins to decrease. This phenomenon makes it possible to explain the processes of system growth, complication and death in biological, economical and physical-engineering systems. We use the linguocombinatorial method of investigation of complex systems, in taking key words for building equivalent equations. This phenomenon is able to increase the adaptability of different systems. The crisis situation is the distance between the adaptation maximum zone and today situation.
\end{abstract}

Keywords: Adaptability, Combinatorial Simulation, Uncertainty, Appearance, Essence, General Systems Theory, Physics, Biology, Social-Economics

\section{Introduction}

The natural language is the main intellectual product of mankind. The structure of the natural intellect is reflected in natural language that is accessible for investigation. Some scientific experiments can be expensive and dangerous. The simulation techniques permit to decrease the cost for investigating these systems. The simulation must accurately reflect the characteristics of the real world. Combinatorial simulation allows studying the full set of system variants including uncertainty. Any system contains some types of uncertainty, which are determined by their existence in real world. Humans interact with both physical objects and their descriptions in terms of natural language, mathematics or tables. Descriptions often only partially represent the essence of real processes. The inaccuracy of description introduces uncertainty. More often the uncertainty of systems is, however, inherent to the real world. This study is aimed toward such types of uncertainty in mental processes. Physical laws, the balance of energy and matter, and information limit the systems behavior. Within these limits, systems interact and adapt to other systems and environment, and undergo destructive actions.

\section{Linguo-Combinatorial Simulation}

Frequently we use the natural language to describe systems. We propose to transfer this natural language description to mathematical equations.
For example, we have a sentence

$$
\text { WORD1 + WORD2 + WORD3 }
$$

where we assign words and only imply meaning of words, the meaning (sense) is ordinary implied but not designated.

We propose to assign meaning in the following form

$$
\begin{gathered}
(\text { WORD1). }(\text { SENSE1 })+(\text { WORD2). }(\text { SENSE2 }) \\
+(\text { WORD3 }) \cdot(\text { SENSE3 })=0
\end{gathered}
$$

This equation (2) can be represented in the following form

$$
\mathrm{A} 1 . \mathrm{E} 1+\mathrm{A} 2 . \mathrm{E} 2+\mathrm{A} 3 . \mathrm{E} 3=0
$$

where Ai, i = 1, 2, 3, will denote words from English Appearance and Ei will denote senses from English Essence. The equations (2) and (3) are the model of the sentence (1). When we have a mathematical equation in the form $\mathrm{F}(\mathrm{x} 1, \mathrm{x} 2, \mathrm{x} 3)=0$, we can turn such a form by means of differentiation where the partial derivatives are the appearances and the derivatives with respect to time are the essences. This model is an algebraic ring and we can resolve this equation with respect to the appearances $\mathrm{Ai}$ or the essences $\operatorname{Ei}[4,5,6]$ :

$$
\begin{array}{rr}
\text { A1 } & \mathrm{U} 1 * \mathrm{E} 2 . \mathrm{U} 2 * \mathrm{E} 3 \\
\mathrm{~A} 2 & \mathrm{U} 1 * \mathrm{E} 1 . \mathrm{U} 3 * \mathrm{E} 3
\end{array}
$$




\section{$\mathrm{A} 3 \sim \mathrm{U} 2 * \mathrm{E} 1-\mathrm{U} 3 * \mathrm{E} 2$}

or

$$
\begin{array}{cc}
\text { E1 } & \mathrm{U} 1 * \mathrm{~A} 2 \\
\text { E2 } & \mathrm{U} 2 * \mathrm{~A} 3 \\
\mathrm{U} 1 * \mathrm{~A} 1 & \mathrm{U} 3 * \mathrm{~A} 3 \\
\mathrm{E} 3 & \mathrm{U} 2 * \mathrm{~A} 1-\mathrm{U} 3 * \mathrm{~A} 2
\end{array}
$$

where U1, U2, U3 are arbitrary coefficients, can be used for solution of different tasks on the initial manifold (2) or (3). In general if we have $n$ variables in our system and $m$ manifolds, restrictions, then the number of arbitrary coefficients $\mathrm{S}$ will be defined as the number of combinations from $\mathrm{n}$ to $\mathrm{m}+1$ [4], as shown in Table 1,

$$
\mathrm{S} \quad C_{n}^{m+1}, n>m
$$

Table 1. The number of arbitrary coefficients depending on the number of variables $n$ and the number of restriction $m$.

\begin{tabular}{lllllllll}
\hline $\mathbf{n} / \mathbf{m}$ & $\mathbf{1}$ & $\mathbf{2}$ & $\mathbf{3}$ & $\mathbf{4}$ & $\mathbf{5}$ & $\mathbf{6}$ & $\mathbf{7}$ & $\mathbf{8}$ \\
\hline 2 & 1 & & & & & & & \\
3 & 3 & 1 & & & & & & \\
4 & 6 & 4 & 1 & & & & & \\
5 & 10 & 10 & 5 & 1 & & & & \\
6 & 15 & 20 & 15 & 6 & 1 & & & \\
7 & 21 & 35 & 35 & 21 & 7 & 1 & & \\
8 & 28 & 56 & 70 & 56 & 28 & 8 & 1 & \\
9 & 36 & 84 & 126 & 126 & 84 & 36 & 9 & 1 \\
\hline
\end{tabular}

The formula (6) is the basic law of cybernetics, informatics and synergetics for complex systems. The number of arbitrary coefficients is the measure of uncertainty. Usually, when solving mathematical systems, the number of variables is equal to the number of equations. In practice we frequently do not know how many constraints there are on our variables. Combinatorial simulation makes it possible to simulate and study the systems with uncertainty on the base of incomplete information. The problem of simulation of condition, guaranteeing the existence of maximum adaptability is investigated.

It is supposed that the behavior of a system with $\mathrm{n}$ variables is given with an accuracy of $m$ intersecting manifolds, $\mathrm{n}>\mathrm{m}$. If the system is considered as a multidimensional generator (Fig.1) where at least a part of the variables interact with environment variables, and if the objective of the system is to decrease the functional of discoordination between them $(\Delta 1 \ldots \Delta \mathrm{k})$, the system control unit has two instruments of impact, $a$ and $b$, upon the system. First, this is the tuning - the changing of uncertain coefficients in the structure of the differential equations of the system, taking account that the greater number of these coefficients implies more accurate system response to changing environment. Second, this is the learning - the imposing new restrictions on the system behavior. The number of arbitrary coefficients, in the structure of equivalent equations, changes in the process of learning, of consecutive imposing new and new restrictions on the system behavior. In the systems with more than six variables the number of arbitrary coefficients increases first, and then, passing through the maximum begins to decrease. This phenomenon makes it possible to explain the processes of system growth, complication and death. The existence of maximum adaptability phenomenon is observed in and proved by numerous biological, economical and physicalengineering systems.

Fig. 1 shows the interaction between system and environment. It is important that we describe a system with a full sum of combinations and have all the variants of decisions. The linguo-combinatorial simulation is a useful heuristic approach for investigation of complex, poorly formalized systems.

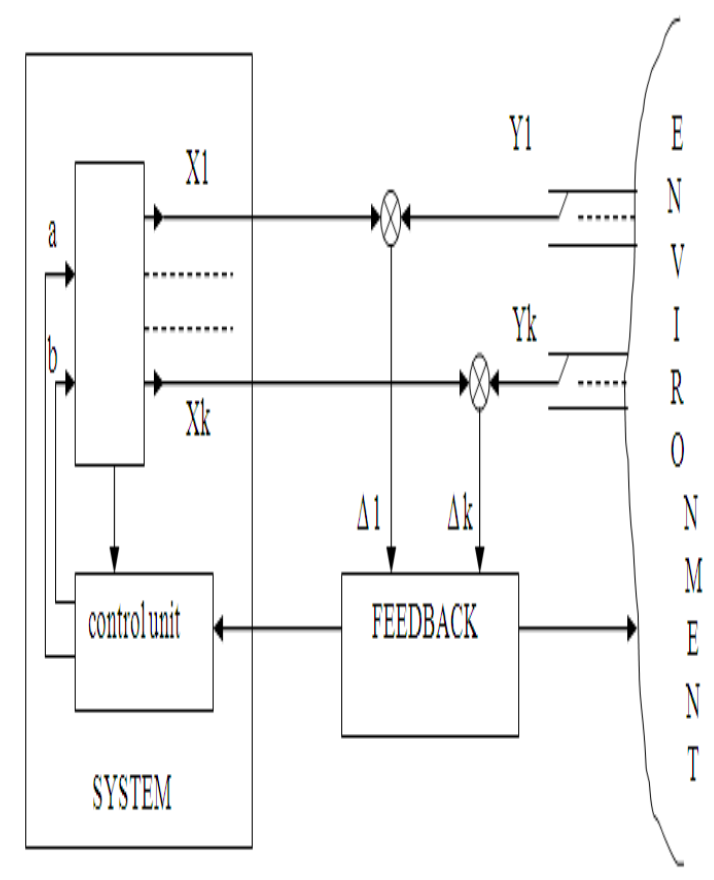

Figure 1. Model of "System-Environment.

Natural language is the main intellectual product of mankind; the structure of natural language reflects the structure of natural intellect of mankind and its separate representatives on the level of consciousness and unconscious. Linguo-combinatorial simulation is the calculation, which permits to extract the senses from texts. Wittgenstein wanted to have the calculation of senses [2,3]. In our calculation we have the three groups of variables: the first group - the words of natural language $\mathrm{A} i$, the second group - the essences Ei, which can be the internal language of brain [1]; we can have the different natural languages, but we have only one internal language of brain; this hypothesis opens a new way for experimental investigation; the third group of variables - the arbitrary coefficients, uncertainty in our model, which we can use for adaptation in translation processes and etc 


\section{Structure of General Model of City}

If we have the key words - Population, Passionarity, Territory, Production, Ecology and Safety, Finance and External Relation for simulation of city [11], then the equation of city will be

$$
\begin{aligned}
& \mathrm{A}^{1}{ }_{1} * \mathrm{E} 1+\mathrm{A}^{1}{ }_{2} * \mathrm{E} 2+\mathrm{A}^{1}{ }_{3} * \mathrm{E} 3+\mathrm{A}^{1}{ }_{4} * \mathrm{E} 4 \\
& +\mathrm{A}^{1}{ }_{5} * \mathrm{E} 5+\mathrm{A}^{1}{ }_{6} * \mathrm{E} 6+\mathrm{A}^{1}{ }_{7} * \mathrm{E} 7=0
\end{aligned}
$$

and the equivalent equations of our model will be.

$$
\begin{aligned}
& \mathrm{E} 1=\mathrm{U} 1 * \mathrm{~A}^{1}{ }_{2}+\mathrm{U} 2 * \mathrm{~A}^{1}{ }_{3}+\mathrm{U} 3 * \mathrm{~A}^{1}{ }_{4}+\mathrm{U} 4 * \mathrm{~A}^{1}{ }_{5}+\mathrm{U} 5 * \mathrm{~A}^{1}{ }_{6}+\mathrm{U} 6 * \mathrm{~A}^{1}{ }_{7} \\
& \mathrm{E} 2=-\mathrm{U} 1 * \mathrm{~A}^{1}{ }_{1}+\mathrm{U} 7 * \mathrm{~A}^{1}{ }_{3}+\mathrm{U} 8 * \mathrm{~A}^{1}{ }_{4}+\mathrm{U} 9 * \mathrm{~A}^{1}{ }_{5}+\mathrm{U} 10 * \mathrm{~A}^{1}{ }_{6}+\mathrm{U} 11^{*} \mathrm{~A}^{1}{ }_{7} \\
& \mathrm{E} 3=-\mathrm{U} 2 * \mathrm{~A}^{1}{ }_{1}-\mathrm{U} 7 * \mathrm{~A}^{1}{ }_{2}+\mathrm{U} 12 * \mathrm{~A}^{1}{ }_{4}+\mathrm{U} 13 * \mathrm{~A}^{1}{ }_{5}+\mathrm{U} 14 * \mathrm{~A}^{1}{ }_{6}+\mathrm{U} 15 * \mathrm{~A}^{1}{ }_{7} \\
& \mathrm{E} 4=-\mathrm{U} 3 * \mathrm{~A}^{1}{ }_{1}-\mathrm{U} 8 * \mathrm{~A}^{1}{ }_{2}-\mathrm{U} 12 * \mathrm{~A}^{1}{ }_{3}+\mathrm{U}_{16} * \mathrm{~A}^{1}{ }_{5}+\mathrm{U} 17 * \mathrm{~A}^{1}{ }_{6}+\mathrm{U} 18 * \mathrm{~A}^{1}{ }_{7} \\
& \mathrm{E} 5=-\mathrm{U} 4 * \mathrm{~A}^{1}{ }_{1}-\mathrm{U} 9 * \mathrm{~A}^{1}{ }_{2}-\mathrm{U} 13 * \mathrm{~A}^{1}{ }_{3}-\mathrm{U}_{16} *^{*} \mathrm{~A}^{1}{ }_{4}+\mathrm{U} 19 * \mathrm{~A}^{1}{ }_{6}+\mathrm{U} 20 * \mathrm{~A}^{1}{ }_{7} \\
& \mathrm{E} 6=-\mathrm{U} 5 * \mathrm{~A}^{1}{ }_{1}-\mathrm{U} 10 * \mathrm{~A}^{1}{ }_{2}-\mathrm{U}_{14} * \mathrm{~A}^{1}{ }_{3}-\mathrm{U}_{17} * \mathrm{~A}^{1}{ }_{4}-\mathrm{U}_{1} *^{*} \mathrm{~A}^{1}{ }_{5}+\mathrm{U} 21 * \mathrm{~A}^{1}{ }_{7} \\
& \mathrm{E} 7=-\mathrm{U} 6 * \mathrm{~A}^{1}{ }_{1}-\mathrm{U} 11 * \mathrm{~A}^{1}{ }_{2}-\mathrm{U} 15^{*} \mathrm{~A}^{1}{ }_{3}-\mathrm{U} 18 * \mathrm{~A}^{1}{ }_{4}-\mathrm{U} 20 * \mathrm{~A}^{1}{ }_{5}-\mathrm{U} 21 * \mathrm{~A}_{6}{ }_{6}
\end{aligned}
$$

where $\mathrm{A}^{1}{ }_{1}$ is a characteristics of population (health, education, employment and etc), E1, a variation of this characteristics, $\mathrm{A}^{1}{ }_{2}$ a characteristics of "passionarity", intentions of social groups of population, E2, a variation of this characteristics, $\mathrm{A}_{3}^{1}$, a characteristics of territory, E3, a variation of this characteristics, $\mathrm{A}^{1}{ }_{4}$, a characteristics of production (industrial, agricultural, science, service etc), E4, a variation of this characteristics, $\mathrm{A}^{1}{ }_{5}$, a characteristics of ecology and safety, E5, a variation of this characteristics, $\mathrm{A}^{1}{ }_{6}$, a characteristics of finance, banking, individual finance etc, E6, a variation of this characteristics, $\mathrm{A}^{1}{ }_{7}$, a characteristics of external relation, input and output flows of material, energy, information, finance, population E7, a variation of this characteristics, $\mathrm{U} 1, \mathrm{U} 2, \ldots \mathrm{U} 21$, arbitrary coefficients, which compose the block of control in our city structure (Fig.2). We will have the same structure for each region, country and world.

If we have two restrictions, $\mathrm{n}=7, \mathrm{~m}=2$, our model of city was described by means of these equations

$$
\begin{gathered}
\mathrm{A}_{1}^{1} * \mathrm{E} 1+\mathrm{A}^{1}{ }_{2} * \mathrm{E} 2+\mathrm{A}_{3}^{1} * \mathrm{E} 3+\mathrm{A}_{4}^{1} * \mathrm{E} 4+ \\
+\mathrm{A}^{1}{ }_{5} * \mathrm{E} 5+\mathrm{A}_{6}^{1} * \mathrm{E} 6+\mathrm{A}^{1}{ }_{7} * \mathrm{E} 7=0 \\
\mathrm{~A}^{2}{ }_{1} * \mathrm{E} 1+\mathrm{A}^{2}{ }_{2} * \mathrm{E} 2+\mathrm{A}^{2}{ }_{3} * \mathrm{E} 3+\mathrm{A}^{2}{ }_{4} * \mathrm{E} 4+ \\
+\mathrm{A}^{2}{ }_{5} * \mathrm{E} 5+\mathrm{A}^{2}{ }_{6} * \mathrm{E} 6+\mathrm{A}^{2}{ }_{7} * \mathrm{E} 7=0
\end{gathered}
$$

The equivalent equations with $\mathrm{S}=35$ will be

$$
\begin{aligned}
\mathrm{E} 1= & \mathrm{U} 1 * \mathrm{D}^{1}{ }_{23}+\mathrm{U} 2 * \mathrm{D}^{1}{ }_{24}+\mathrm{U} 3 *^{\mathrm{D}^{1}{ }_{25}+} \\
& +\mathrm{U} 4 * \mathrm{D}^{1}{ }_{26}+\ldots+\mathrm{U} 15 * \mathrm{D}^{1}{ }_{67} \\
\mathrm{E} 2= & -\mathrm{U} 1 * \mathrm{D}^{2}{ }_{13}-\mathrm{U} 2 * \mathrm{D}^{2}{ }_{14}-\mathrm{U} 3 * \mathrm{D}^{2}{ }_{15}- \\
& \mathrm{U} 4 * \mathrm{D}^{2}{ }_{16}-\ldots+\mathrm{U} 25 * \mathrm{D}^{2}{ }_{67} \\
\mathrm{E} 7= & \mathrm{U} 5 * \mathrm{D}^{7}{ }_{12}+\mathrm{U} 9 * \mathrm{D}^{7}{ }_{13}+\mathrm{U} 12 * \mathrm{D}^{7}{ }_{14}+ \\
& +\mathrm{U} 14 * \mathrm{D}^{7}{ }_{15}+\ldots+\mathrm{U} 35 * \mathrm{D}^{7}{ }_{56}
\end{aligned}
$$

where $D_{12}=A^{1}{ }_{1} * A^{2}{ }_{2}-A^{1}{ }_{2} * A^{2}{ }_{1}$ and etc. After covering the new restriction the structure of equivalent equations is changed.

We can introduce the new variables in our model. For example, we can consider three group of population young people (including children) A1, working people A2 and old people (including pension people) A3, then the city equation will consist nine variables:

$$
\mathrm{A} 1 * \mathrm{E} 1+\mathrm{A} 2 * \mathrm{E} 2+\ldots+\mathrm{A} 9 * \mathrm{E} 9=0
$$

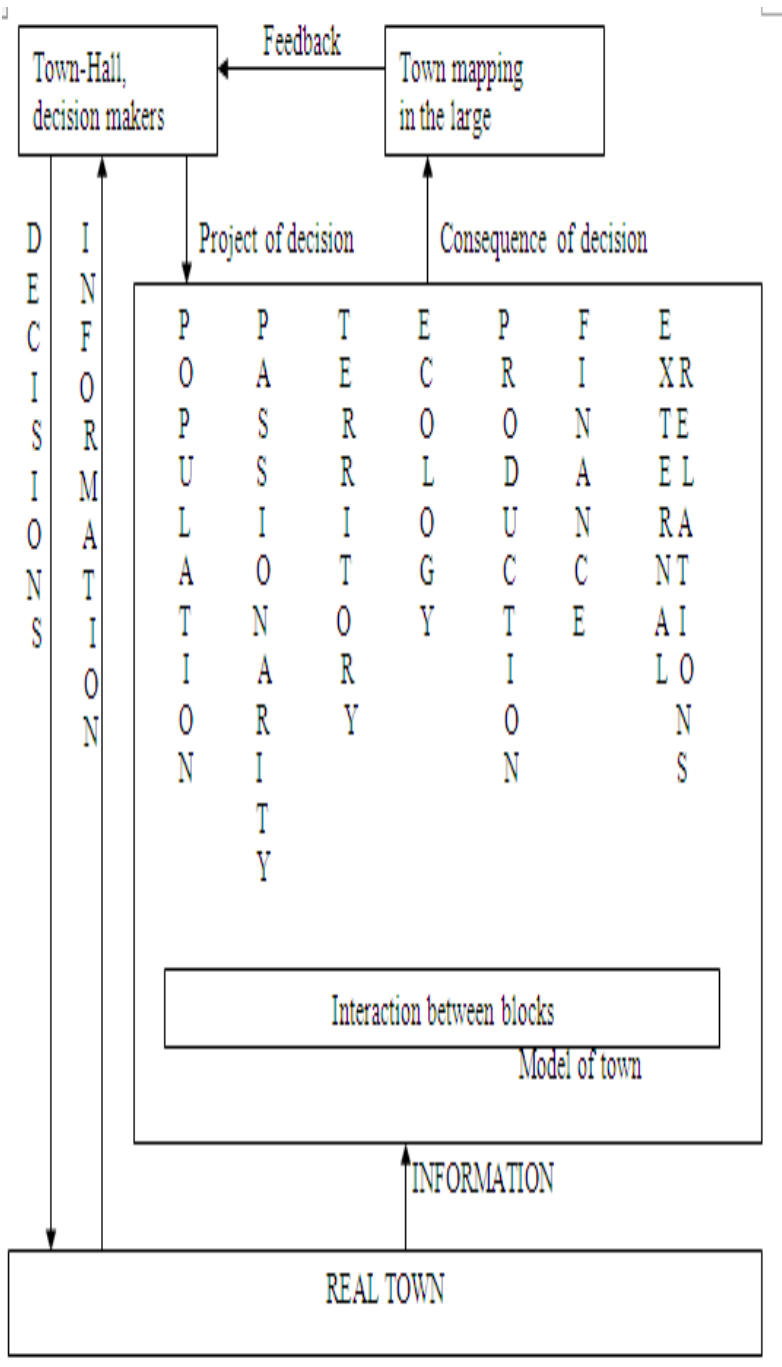

Figure 2. Simulation of a town for decisions making support. 
where:

A1 - characteristic of young people group, E1 - variation of this characteristic,

A2 - characteristic of working people group, E2 - variation of this characteristic,

A3 - characteristic of old people group, E3 - variation of this characteristic,

A4 - characteristic of passionarity, E4 - variation of this characteristic,

A5 - characteristic of territory, E5 - variation of this characteristic,

A6 - characteristic of production, E6-variation of this characteristic,

A7 - characteristic of ecology and safety, E7-variation of this characteristic,

A8 - characteristic of finance, E8 - variation of this characteristic,

A9 - characteristic of external relations, E9 - variation of this characteristic.

The structure of equivalent equations of city model will be $(12) \mathrm{E} 1=\mathrm{U} 1 * \mathrm{~A} 2+\mathrm{U} 2 * \mathrm{~A} 3+\mathrm{U} 3 * \mathrm{~A} 4+\mathrm{U} 4 * \mathrm{~A} 5+\mathrm{U} 5 * \mathrm{~A} 6+$ $\mathrm{U} 6 * \mathrm{~A} 7+\mathrm{U} 7 * \mathrm{~A} 8+\mathrm{U} 8 * \mathrm{~A} 9$

$$
\begin{aligned}
& \mathrm{E} 2=-\mathrm{U} 1 * \mathrm{~A} 1+\mathrm{U} 9 * \mathrm{~A} 3+\mathrm{U} 10 * \mathrm{~A} 4+\mathrm{U} 11 * \mathrm{~A} 5++\mathrm{U} 12 * \mathrm{~A} 6+\mathrm{U} 13 * \mathrm{~A} 7+\mathrm{U} 14 * \mathrm{~A} 8+\mathrm{U} 15 * \mathrm{~A} 9 \\
& \mathrm{E} 3=-\mathrm{U} 2 * \mathrm{~A} 1-\mathrm{U} 9 * \mathrm{~A} 2+\mathrm{U} 16 * \mathrm{~A} 4+\mathrm{U} 17 * \mathrm{~A} 5++\mathrm{U} 18 * \mathrm{~A} 6+\mathrm{U} 19 * \mathrm{~A} 7+\mathrm{U} 20 * \mathrm{~A} 8+\mathrm{U} 21 * \mathrm{~A} 9 \\
& \mathrm{E} 4=-\mathrm{U} 3 * \mathrm{~A} 1-\mathrm{U} 10 * \mathrm{~A} 2-\mathrm{U} 16 * \mathrm{~A} 3++\mathrm{U} 22 * \mathrm{~A} 5+\mathrm{U} 23 * \mathrm{~A} 6+\mathrm{U} 24 * \mathrm{~A} 7+\mathrm{U} 25 * \mathrm{~A} 8+\mathrm{U} 26 * \mathrm{~A} 9 \\
& \mathrm{E} 5=-\mathrm{U} 4 * \mathrm{~A} 1-\mathrm{U} 11 * \mathrm{~A} 2-\mathrm{U} 17 * \mathrm{~A} 3-\mathrm{U} 22 * \mathrm{~A} 4+\mathrm{U} 27 * \mathrm{~A} 6+\mathrm{U} 28 * \mathrm{~A} 7+\mathrm{U} 29 * \mathrm{~A} 8+\mathrm{U} 30 * \mathrm{~A} 9 \\
& \mathrm{E} 6=-\mathrm{U} 5 * \mathrm{~A} 1-\mathrm{U} 12 * \mathrm{~A} 2-\mathrm{U} 18 * \mathrm{~A} 3-\mathrm{U} 23 * \mathrm{~A} 4-\mathrm{U} 27 * \mathrm{~A} 5+\mathrm{U} 31 * \mathrm{~A} 7+\mathrm{U} 32 * \mathrm{~A} 8+\mathrm{U} 33 * \mathrm{~A} 9 \\
& \mathrm{E} 7=-\mathrm{U} 6 * \mathrm{~A} 1-\mathrm{U} 13 * \mathrm{~A} 2-\mathrm{U} 19 * \mathrm{~A} 3-\mathrm{U} 24 * \mathrm{~A} 4-\mathrm{U} 28 * \mathrm{~A} 5-\mathrm{U} 31 * \mathrm{~A} 6+\mathrm{U} 34 * \mathrm{~A} 8+\mathrm{U} 35 * \mathrm{~A} 9 \\
& \mathrm{E} 8=-\mathrm{U} 7 * \mathrm{~A} 1-\mathrm{U} 14 * \mathrm{~A} 2-\mathrm{U} 20 * \mathrm{~A} 3-\mathrm{U} 25 * \mathrm{~A} 4-\mathrm{U} 29 * \mathrm{~A} 5-\mathrm{U} 32 * \mathrm{~A} 6-\mathrm{U} 34 * \mathrm{~A} 7+\mathrm{U} 36 * \mathrm{~A} 9 \\
& \mathrm{E} 9=-\mathrm{U} 8 * \mathrm{~A} 1-\mathrm{U} 15 * \mathrm{~A} 2-\mathrm{U} 21 * \mathrm{~A} 3-\mathrm{U} 26 * \mathrm{~A} 4-\mathrm{U} 30 * \mathrm{~A} 5-\mathrm{U} 33 * \mathrm{~A} 6-\mathrm{U} 35 * \mathrm{~A} 7-\mathrm{U} 36 * \mathrm{~A} 8
\end{aligned}
$$

where U1, U2, . . ,U36 - the arbitrary coefficients, which can be used for tuning of the model.

In general we have the representative point of our system in parameters space, each system has the zone of "health", where the parameters correspond the "health" of concrete system. During "illness" the representative point of organism is found in another zone of parameters - in "illness", crisis zone. The process of treatment is the movement of the representative point from "illness" zone to "health" zone.

In our example the equation of "illness" system will be

$$
\begin{aligned}
& (X 1-X 10)^{2}+(X 2-X 11)^{2}+(X 3-X 12)^{2}+ \\
& +(X 4-X 13)^{2}+(X 5-X 14)^{2}+(X 6-X 15)^{2}+ \\
& +(X 7-X 16)^{2}+(X 8-X 17)^{2}+(X 9-X 18)^{2} \\
& =(X 19)^{2}
\end{aligned}
$$

where $\mathrm{X} 1, \mathrm{X} 2, \ldots, \mathrm{X} 9$ - characteristics of "health" system, $\mathrm{X} 10, \mathrm{X} 11, \ldots, \mathrm{X} 18$ - characteristics of "illness", crisis system, X19 - the distance between health zone and illness zone. For system (13) we can create the equivalent equations system according to type $(2,3)$ and can use the arbitrary coefficients for simulation of "physician" actions. The "physician" actions must decrease the variable X19 and return the representative point from "illness" zone to "health" zone. We have a lot of examples of application of this approach. For example, before Second World War we had a lot of deep crisises, but after Second World War the number and depth of crisises reduced by means of governmental regulation and another new restrictions [15].

\section{Maximum Adaptability Phenomenon}

The equivalent equations of any system contain arbitrary coefficients, which can be used for controlling it. The control may be internal or external. The behavior of any system with an environment contact will be determined by means of formula (6), which is the main law of cybernetics.

Each organism has a maximum adaptability zone. Table 2 shows the mortality depending on the age as a result of the census in Russia in different times. The minimum of mortality is observed within 10-14 ages in different historical periods. The minimum of mortality is identified with the maximum adaptability. Having passed through the maximum adaptability zone, the organism has got the possibility of reproduction.

Table 2. The mortality depending on the age as a result of the census in Russia in different times.

\begin{tabular}{lllllll}
\hline Years/ages & $\mathbf{1 8 9 6 -}$ & $\mathbf{1 9 5 8 -}$ & $\mathbf{1 9 6 9 -}$ & $\mathbf{1 9 7 8 -}$ & $\mathbf{1 9 8 2 -}$ & $\mathbf{1 9 8 4 -}$ \\
& $\mathbf{1 8 9 7}$ & $\mathbf{1 9 5 9}$ & $\mathbf{1 9 7 0}$ & $\mathbf{1 9 8 0}$ & $\mathbf{1 9 8 3}$ & $\mathbf{1 9 8 5}$ \\
\hline $\mathbf{0 - 4}$ & 133,0 & 11,9 & 6,9 & 8,1 & 7,9 & 7,7 \\
$\mathbf{5}-\mathbf{9}$ & 12,9 & 1,1 & 0,7 & 0,7 & 0,6 & 0,6 \\
$\mathbf{1 0}-\mathbf{1 4}$ & 5,4 & 0,8 & 0,6 & 0,5 & 0,5 & 0,5 \\
$\mathbf{1 5}-\mathbf{1 9}$ & 5,8 & 1,3 & 1,0 & 1,0 & 1,0 & 0,9 \\
$\mathbf{2 0}-\mathbf{2 4}$ & 7,6 & 1,8 & 1,6 & 1,7 & 1,6 & 1,5 \\
$\mathbf{2 5}-\mathbf{2 9}$ & 8,2 & 2,2 & 2,2 & 2,3 & 2,2 & 2,0 \\
$\mathbf{3 0}-\mathbf{3 4}$ & 8,7 & 2,6 & 2,8 & 2,9 & 2,9 & 2,8 \\
$\mathbf{3 5}-\mathbf{3 9}$ & 10,3 & 3,1 & 3,7 & 4,3 & 3,8 & 3,6 \\
$\mathbf{4 0}-\mathbf{4 4}$ & 11,8 & 4,0 & 4,7 & 5,4 & 5,6 & 5,7 \\
$\mathbf{4 5}-\mathbf{4 9}$ & 15,7 & 5,4 & 6,0 & 7,8 & 7,4 & 7,3 \\
$\mathbf{5 0}-\mathbf{5 4}$ & 18,5 & 7,9 & 8,7 & 10,3 & 10,9 & 11,3 \\
\hline
\end{tabular}

Fig. 3 shows the evolution of system, the cycle of development begins in point 1 , passes the maximum of the arbitrary coefficients number, and finishes in point 2 , where the system must have the transformation, forgetting old restrictions, after new cycle begin in point 3 and etc. Maximum 
adaptability phenomenon makes it possible to explain different cycles in biological and socio-economical systems, for example, Kondratiev cycles. Each enterprise must be within maximum adaptability zone if we would like to retain this enterprise in changes flow. The sustainable development of systems can be only within maximum adaptability zone. The sustainable thermonuclear reaction is possible only within this zone.

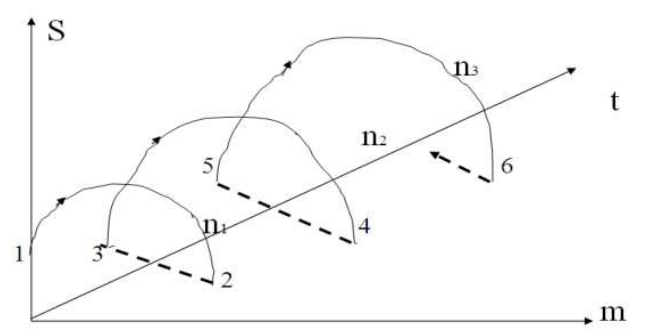

Figure 3. Transformation of developing system, $n 1<n 2<n 3$, trajectory of system: 1-2-3-4-5-6-...,dotted lines - creative processes, compact lines - evolutionary processes.

For retaining the system within maximum adaptability zone, we have the different instruments - increasing the variables number, imposing new restrictions or removing the old ones etc. For example, we can joint different systems in an integral system to increase or decrease the adaptability of systems. So, from the two following systems

$$
\text { S1 } \quad C_{n 1}^{m 1+1} \text { and S2 } C_{n 2}^{m 2+1}
$$

we can joint them in imposing new restrictions, mcol, in view of obtaining the new collective system

$$
\text { Scol } C_{n 1+n 2}^{m 1+m 2+m c o l}
$$

where the adaptability of this new system can be either $\mathrm{Scol}>\mathrm{S} 1+\mathrm{S} 2$ or $\mathrm{Scol}<\mathrm{S} 1+\mathrm{S} 2$ depending upon concrete parameters. We can only see the collective, total effect.

\section{Conclusion}

The combinatorial simulation is a universal method for simulation and modeling. With it, it is possible to create a new model in different areas - in physics, chemistry, biology, psychology, etc. The linguistic basement of the simulation determines the universality of this method: the natural language is the universal sign system and the linguocombinatorial simulation is thus the simulation method, perhaps, of everything. We have tried to show different levels of models. For reliability, each system must be then within maximum adaptability zone. In our model we can see the full interconnection between different variables and control situations. We have the crisis situation when we have the big distance between maximum adaptability zone and our today situation. The crisis situations are the immanent property of complex economical systems. We have a lot of very important economical investigations $[15,16]$, but socio-economical systems are very complicated and it is necessary to use the result from the theory of complex systems.

\section{References}

[1] Augustinus Sanctus(1864) Opera omnia. P.

[2] Morick H. (Ed) (1967) Wittgenstein and the problem of other mind. N.Y.

[3] Morrison J.C. (1968) Meaning and truth in Wittgenstein tractatus. Hague-P.

[4] Ignatiev M.B. (1963) "Golonomical automatic systems", Publ..AN USSR, Moscow-Leningrad, 204 p.

[5] Ignatiev.M.B. (1993)."Simulation of Adaptational Maximim Phenomenon in Developing Systems" Proceedings of The SIMTEC'93 - 1993 International Simulation Technology Conference, San Francisco, USA.

[6] Ignatyev M.B., D.M.Makina, N.N.Petrischev, I.V.Poliakov, E.V.Ulrich, A.V. Gubin (2000) "Global model of organism for decision making support" Proceedings of the High Performance Computing Symposium - HPC 2000, Ed. A. Tentner, 2000 Advanced Simulation Technologies Conference, Washington D.C. USA p.66-71.

[7] Ignatyev M. (2002) "Linguo-combinatorial world picture and reality cognition" Congress-2002 Proceedings "Fundamental problems of natural sciences and engineering" Part 2, St-Petersburg, Russia, p. 116-128.

[8] Ignatyev M.B. (2002) "Linguo-combinatorial method for complex systems simulation" Proceedings of the 6th World Multiconference on Systemics, Cybernetics and Informatics, vol.XI, Computer science II, Orlando, USA p.224-227.

[9] Ignatyev M.B. (2003)“'Seven-blocks model of city for decisions making support " Proceedings of the seminar "Computer models of urban development" St-Petersburg, Russia, p.40-45.

[10] Ignatyev M.(2006) "The study of the adaptational phenomenon in complex systems". CASYS'05 - Seventh International Conference, edited by D.M.Dubois, published by The American Institute of Physics, Melville, NY, AIP Conference Proceedings vol.839, pp.322-330.

[11] Ignatyev M.B.(2008) "Semantics and selforganization in nanoscale physics" International Journal of Computing Anticipatory Systems, vol.22, Edited by D.M.Dubois, CHAOS, Liege, Belgium, pp.17-23.

[12] Ignatyev M.B.(2009) "World Crisis and Innovations flow" Proceedings of the International Conference of Education Informatics and Sustainable Development Problems, StPetersburg,pp.8-22.

[13] Ignatyev M.(2011) "Cybernetics picture of world" StPetersburg, monograph, $448 \mathrm{p}$.

[14] Ignatyev M. (2012) "linguo-combinatorial Simulation of complex systems" Proceedings of ECCS-2012, Bruxelles.

[15] Samuelson P.A., Nordhaus W.D.(2010) “ Economics” 18th edition, McGrow-Hill, 1358 p.

[16] McConnell C.R, Brue S.L, Flynn S.M. (2010) "Economics. Principles, problems and policies" 18 th edition, McGrowHill, 1010 p. 